\title{
Outcomes of Salvage Prostate Cryotherapy: Real-life Experience of a Portuguese Oncologic Hospital
}

 \\ 1 Urology Resident, Hospital Beatriz Ângelo Loures, Portugal \\ 2Urology Resident, Hospital Pedro Hispano, Matosinhos, Portugal \\ 3Urology Consultants, Instituto Português de Oncologia do Porto, Porto, Portugal
}

\section{What's known on the subject? and What does the study add?}

Our study present the outcomes of an underused therapeutic tool on recurrent prostate cancer setting. Until RCTs are performed and available, series such as ours may help to select the best candidates to perform salvage prostate cryotherapy.

\begin{abstract}
Objective: This study aimed to analyze the outcomes of patients with recurrent prostate cancer (PCa) who received salvage cryotherapy (SC) in our institution. Biochemical recurrence (BCR) after definitive radiotherapy or brachytherapy for PCa is usually managed with long-term androgendeprivation therapy (ADT). In selected cases, salvage therapies might delay ADT and its side effects.

Materials and Methods: All patients who received SC from 2014 to 2018 in our institution were evaluated retrospectively.

Results: A total of 17 patients were included, with a median age at SC of 72.0 (range 60-77) years. The median prostate-specific antigen (PSA) before SC was 4.25 [interquartile range (IOR) 3.1-7.6] ng/mL. The median time to BCR was 18.8 (IOR 13.5-32.1) months after SC. The median PSA nadir after SC was 0.49 (IQR 0.09-1.0) ng/mL. With a median follow-up of 43 (range, 11-78) months, 7 (41\%) patients had a recurrence. Of those patients, two received ADT, while others were managed conservatively. The biochemical progression-free survival (bPFS) time of patients with PSA nadir $<0.5 \mathrm{ng} / \mathrm{mL}$ was 56.0 vs. 22.5 months (log-rank test, $\mathrm{p}=0.012$ ). Gleason score $\geq 8$ at diagnosis and PSA before SC $>8 \mathrm{ng} / \mathrm{mL}$ were also associated with shorter bPFS (log-rank test, $\mathrm{p}<0.05)$. De novo urinary incontinence was reported in $5(29.4 \%)$ patients. The 3 - and 5 -year PCa-specific survival rates were $93.3 \%$ and $85.6 \%$, respectively.

Conclusion: SC might be considered with acceptable oncological and functional results. Until randomized controlled trials are performed and available, series such as ours may help widen our views on all therapeutic possibilities after primary treatment failure in PCa.
\end{abstract}

Keywords: Recurrent prostate cancer, biochemical recurrence, salvage prostate cryotherapy

\section{Introduction}

Prostate cancer ( $\mathrm{PCa}$ ) is the second most common cancer in men worldwide and is currently the second cause of cancerrelated deaths in the USA and Europe (1). After primary curative treatment with radical prostatectomy or radiotherapy (RT), approximately $27 \%-53 \%$ of patients will experience biochemical recurrence (BCR) (2). Biochemical failure after definitive RT or brachytherapy (BT) is usually managed conservatively or with long-term androgen-deprivation therapy (ADT), and only a small proportion of the patients received salvage treatment (3).
Imaging is the cornerstone of proper staging, allowing distinguishing between local and distant recurrence and, ultimately, selecting those who might benefit from local treatment, such as radical prostatectomy, high-intensity focused ultrasound (HIFU), or prostate cryoablation. Salvage cryotherapy (SC) has gained increasing attention as it has a lower morbidity rate than salvage radical prostatectomy (SRP) (4). In this study, we aimed to report the oncological and functional outcomes of $\mathrm{SC}$ in our institution.

Correspondence: Luisa Jerónimo Alves, Urology Resident, Hospital Beatriz Ângelo Loures, Portugal

Phone: +351 $917903692 \quad$ E-mail: luisa.jeronimoaloves@gmail.com ORCID-ID: orcid.org/0000-0002-5346-1789

Received: 15.02.2021 Accepted: 17.04.2021

Cite this article as: Jerónimo Alves L, Catarino R, Pereira J, Freitas R, Braga I, Morais A. Outcomes of Salvage Prostate Cryotherapy: Real-life Experience of a Portuguese Oncologic Hospital. J Urol Surg 2021;8(3):173-178.

๑Copyright 2021 by the Association of Urological Surgery / Journal of Urological Surgery published by Galenos Publishing House. 


\section{Materials and Methods}

We reviewed medical records of 17 patients who submitted to SC from 2014 to 2018 after PCa recurrence following low-dose BT or RT.

The International Society of Urological Pathology (ISUP) grading system was used to report all prostate biopsies (including prognostic Gleason scores 1-5). Patients with PSA levels increasing after RT or BT underwent multiparametric-prostate magnetic resonance imaging (mpMRI), PET-prostate-specific membrane antigen, and prostate transperineal template guided mapping biopsy (TPMB), as appropriate. TPMB was performed following the template proposed by Ginsburg Study Group, which comprises a systematic distribution of prostatic cores in defined sectors (anterior, middle, and posterior sectors), in number 4 from the medial to the lateral in each sector and lobe (5).

After a multidisciplinary meeting, SC was offered to patients with PSA level $<20 \mathrm{ng} / \mathrm{mL}$, with exclusive local PCa recurrence and life expectancy superior to 10 years.

Salvage focal cryoablation (SFC) was defined as hemi-ablation of a single lobe of the prostate, while salvage total cryoablation (STC) included the whole gland. SFC was proposed to patients with biopsy-proven unilateral recurrent PCa.

Cryoprobes were placed transperineally using a free-hand technique under ultrasound guidance. Then, two freeze-thaw cycles were performed with a urethral warming device to prevent urethral tissue damage. Rapid freezing causes ice ball formation, monitored by ultrasonography, reaching $-40{ }^{\circ} \mathrm{C}$ in the target zone. A thermal sensor was positioned in the prerectal fatty tissue, and as soon as the temperature reached $0{ }^{\circ} \mathrm{C}$, passive thawing was started. Patients were discharged on day 1 , and the bladder catheter was removed on postoperative day 7 . Analgesics on-demand and an alpha-blocker for 30 days were prescribed.

PSA levels and functional outcomes were assessed at 3,6, and 12 months on the first year after surgery and then every 6 months. De novo urinary incontinence (UI) was defined as the use of any pad, and de novo sexual dysfunction was defined as a new onset of erection inability during sexual intercourse, with or without the use of inhibitors of phosphodiesterase type 5 .

BCR was defined according to the Phoenix criteria (nadir PSA plus $2 \mathrm{ng} / \mathrm{mL}$ ) either following primary (first $\mathrm{BCR}$ ) or salvage (second $\mathrm{BCR}$ ) therapies. The primary endpoint was biochemical progression-free survival (bPFS) after SC. Additionally, the overall survival and functional outcomes were assessed.

The institutional ethics committee conceded the approval for data collection, analysis, and publication of this retrospective study.

\section{Statistical Analysis}

Statistical analyses were performed with SPSS version 24 Categorical variables were compared using the chi-square test. Survival curves were established using the Kaplan-Meier method and compared using the log-rank test. Multivariable analysis using the Cox proportional hazards model was performed to evaluate the effect of risk factors on BCR after SC. In all tests, $p<0.05$ was considered to indicate significance.

\section{Results}

Patient characteristics are listed in Table 1. A total of 17 patients were included, with a median age of 72 (range, 6077) years. Of those, $15(88 \%)$ received primary RT and $2(12 \%)$ received BT. Nine patients from the RT group received adjuvant ADT, and all had ISUP grade $\geq 3$ or ISUP grade 2 with $>50 \%$ positive cores on prostate systematic biopsy. At diagnosis, the median PSA level was 9.0 [interquartile range (IQR) 7.4-12.2] $\mathrm{ng} / \mathrm{mL}$, and $8(47 \%)$ patients belonged to the high-risk group, according to the D'Amico classification. The median time to the first BCR was 77.0 (IQR 64.6-107.1) months. Two patients whose diagnosis were based on prostate mpMRI did not undergo TMPB. Eleven patients received STC, and six patients received SFC with a median PSA level of 4.25 (IQR 70-74.6) $\mathrm{ng} / \mathrm{mL}$ at the time of the procedure. All patients stayed at the hospital stay for 2 days, and no major surgical complications were recorded. Two cases of acute urinary retention were reported in the STC group, which was managed conservatively. Long-term postoperative complications are described in Table 2. Eight patients had postSC PSA nadir $<0.5 \mathrm{ng} / \mathrm{mL}$, with a median PSA nadir of 0.49 (IQR $0.09-1.0) \mathrm{ng} / \mathrm{mL}$.

Figure 1 illustrates the Kaplan-Meier curve of bPFS after SC of all patients. The 3-year and 5-year bPFS rates were $47.5 \%$ and $17.8 \%$, respectively. At a median follow-up of 43.2 (IQR 32.3-40.4) months, 7 (41\%) patients experienced recurrence. Of these patients, one was diagnosed with a regional lymph node recurrence and received stereotactic body radiation therapy, two patients received ADT, and the remaining patients were managed conservatively. The median time to the second BCR was 18.8 (IQR 13.5-32.1) months.

The bPFS times were significantly different according to the preSC PSA level, with an estimated mean bPFS time of 46.1 months in patients with pre-SC PSA level $<8 \mathrm{ng} / \mathrm{mL}$, compared with 18.8 months in patients with pre-SC PSA level $<8 \mathrm{ng} / \mathrm{mL}$ (log-rank test, $p=0.03$ ) (Figure 2a). Furthermore, the post-SC PSA nadir $\geq 0.5 \mathrm{ng} / \mathrm{mL}$ was also associated with shorter bPFS, with a mean of 22.5 months compared with 56.0 months of those with postSC PSA nadir $<0.5 \mathrm{ng} / \mathrm{mL}$ (log-rank test, $\mathrm{p}=0.012$ ) (Figure $2 \mathrm{~b}$ ). ISUP $\geq 4$ and clinical T-stage $\geq 3$ a at diagnosis and the extent of 
SC (STC vs. SFC) did not show significant difference regarding bPFS (Log-rank test, $p>0.05$ ).

Table 3 lists the clinicopathological parameters that may predict the second BCR as analyzed by univariate Cox regression analysis.

As shown in the table, ISUP at diagnosis $[\geq 4$; hazard ratio (HR) 9.51, 95\% confidence interval $(\mathrm{Cl}) 1.32-68.80, p=0.026]$, time to first $\mathrm{BCR}(<6 ; \mathrm{HR} 2.22 ; 95 \% \mathrm{Cl} 0.46-10.79, p=0.035)$, pre-

\begin{tabular}{|c|c|}
\hline Patient characteristics & Total $(n=17)$ \\
\hline Age at $\mathrm{SC}$, median (range), years & $72(60-77)$ \\
\hline PSA at diagnosis, median (IOR), $\mathrm{ng} / \mathrm{mL}$ & $9.0(7.4-12.2)$ \\
\hline \multicolumn{2}{|l|}{ D'Amico risk at diagnosis, $\mathrm{n}(\%)$} \\
\hline Low & $3(17.6)$ \\
\hline Intermediate & $6(35.3)$ \\
\hline High & $8(47.1)$ \\
\hline \multicolumn{2}{|l|}{ Clinical stage at diagnosis, $\mathrm{n}(\%)$} \\
\hline T1c & $5(29.4)$ \\
\hline T2a & $5(29.4)$ \\
\hline $\mathrm{T} 2 \mathrm{c}$ & $3(17.6)$ \\
\hline$\geqslant \mathrm{T} 3$ & $4(23.5)$ \\
\hline \multicolumn{2}{|l|}{ ISUP grade at biopsy at diagnosis, $\mathrm{n}(\%)$} \\
\hline 1 & $7(41.2)$ \\
\hline 2 & $6(35.3)$ \\
\hline 3 & $2(11.8)$ \\
\hline$\geqslant 4$ & $2(11.8)$ \\
\hline \multicolumn{2}{|l|}{ Type of $1^{\text {st }}$-line treatment } \\
\hline RT & $15(88.2)$ \\
\hline BT & $2(11.8)$ \\
\hline Adjuvant ADT, n (\%) & $9(52.9)$ \\
\hline $\begin{array}{l}\text { PSA-nadir post } 1^{\text {st }} \text {-line treatment, median } \\
(\text { IOR), ng/mL }\end{array}$ & $0.5(0.08-1.05)$ \\
\hline Time to $1^{\text {st }}$-PSA-nadir, median (IQR), mo & $19.0(11.5-31)$ \\
\hline Time to $1^{\text {st }}-B C R$, median (IQR), mo & $77.0(64.6-107.1)$ \\
\hline \multicolumn{2}{|l|}{ Cryotherapy, n (\%) } \\
\hline Whole-gland (STC) & $11(64.7)$ \\
\hline Hemi-gland (SFC) & $6(35.3)$ \\
\hline PSA-pre SC, median (IQR), ng/mL & $4.3(3.1-7.6)$ \\
\hline PSA-nadir post SC, median (IQR), ng/mL & $0.5(0.09-1.0)$ \\
\hline Time to $2^{\text {nd }}-P S A-$ nadir, median (IOR), mo & $3.9(3.0-7.0)$ \\
\hline Time to $2^{\text {nd }}-B C R$, median (IOR), mo & $18.8(13.5-32.1)$ \\
\hline Follow-up period, median (IQR), mo & $43.2(32.3-50.4)$ \\
\hline \multicolumn{2}{|c|}{$\begin{array}{l}\text { IQR: Interquartile range, PSA: Prostate-specific antigen, ISUP: International Society } \\
\text { of Urological Pathology, RT: Radiation therapy, BT: Brachytherapy, ADT: Androgen } \\
\text { deprivation therapy, BCR: Biochemical recurrence, Mo: months, SC: Salvage } \\
\text { cryotherapy }\end{array}$} \\
\hline
\end{tabular}

SC PSA ( $\geq 8 ; \mathrm{HR} 3.94,95 \% \mathrm{Cl} 1.04-14.99, \mathrm{p}=0.044)$, and postSC PSA nadir ( $\geq 0.5$; HR $0.10,95 \% \mathrm{Cl} 0.12-0.88, p=0.038$ ) and pathological T stage at diagnosis ( $\geq 3 \mathrm{a}$; HR $2.33,95 \% \mathrm{Cl} 1.03-$ 5.29, $p=0.043$ ) were associated with the second $B C R$.

Multivariate Cox regression analysis was performed with the time to the first $\mathrm{BCR}<6$ years ( $\mathrm{HR} 3.94,95 \% \mathrm{Cl} 0.65-23.94$, $\mathrm{p}=0.137)$, pre-SC PSA level $\geq 8 \mathrm{ng} / \mathrm{mL}(\mathrm{HR} 5.05,95 \% \mathrm{Cl} 0.63$ -

\begin{tabular}{|l|l|l|l|}
\hline \multicolumn{4}{|l|}{ Table 2. Long-term complications } \\
\hline Long-term complications & $\begin{array}{l}\text { STC } \\
(\mathbf{n}=11)\end{array}$ & $\begin{array}{l}\text { SFC } \\
(\mathbf{n}=6)\end{array}$ & $\begin{array}{l}\text { Total } \\
(\mathbf{n}=17)\end{array}$ \\
\hline $\begin{array}{l}\text { De novo urinary incontinence, } \\
\mathrm{n}(\%)\end{array}$ & $4(36.4)$ & $1(16.7)$ & $5(29.4)$ \\
\hline $\begin{array}{l}\text { De novo erectile dysfunction, } \\
\mathrm{n}(\%)\end{array}$ & $1(9.1)$ & $1(16.7)$ & $2(11.8)$ \\
\hline Chronic perineal pain, n (\%) & $2(18.2)$ & $1(16.7)$ & $3(17.6)$ \\
\hline STC: Salvage total cryotherapy, SFC: Salvage focal cryotherapy \\
\hline
\end{tabular}

Table 3. Univariate cox regression analysis of factors associated with bPFS of our study cohort

\begin{tabular}{|l|l|l|l|l|}
\hline \multirow{2}{*}{ Variables } & Category & \multicolumn{3}{l}{ Univariate } \\
\cline { 3 - 5 } & & HR & $\mathbf{9 5} \% \mathbf{C l}$ & $\mathbf{p}$-value \\
\hline $\begin{array}{l}\text { Pathological } \\
\text { T-stage }\end{array}$ & $<3 a$ vs $\geq 3 \mathrm{a}$ & 1.65 & $0.32-8.60$ & 0.55 \\
\hline $\begin{array}{l}\text { High-risk D'Amico } \\
\text { at diagnosis }\end{array}$ & 0 vs 1 & 0.89 & $0.24-3.23$ & 0.89 \\
\hline $\begin{array}{l}\text { Time-to-1 } \\
\text { (years) }\end{array}$ & $\geq 6$ vs $<6$ & 2.22 & $0.46-10.79$ & 0.035 \\
\hline $\begin{array}{l}\text { PSA pre-SC } \\
\text { (ng/mL) }\end{array}$ & $<8$ vs $\geq 8$ & 3.94 & $1.04-14.99$ & 0.044 \\
\hline $\begin{array}{l}\text { PSA-nadir post SC } \\
\text { PSA }\end{array}$ & $<0.5$ vs $\geq 0.5$ & 0.10 & $0.12-0.88$ & 0.038 \\
\hline $\begin{array}{l}\text { ISUP: International Society of Urological Pathology, PSA: Prostate-specific antigen, } \\
\text { BCR: Biochemical recurrence, SC: Salvage cryotherapy, HR: Hazard ratio, Cl: Confidence } \\
\text { interval }\end{array}$
\end{tabular}



Figure 1. Kaplan-Meier curves of the biochemical progression-free survival of patients with recurrent prostate cancer treated with salvage cryotherapy in our institution 

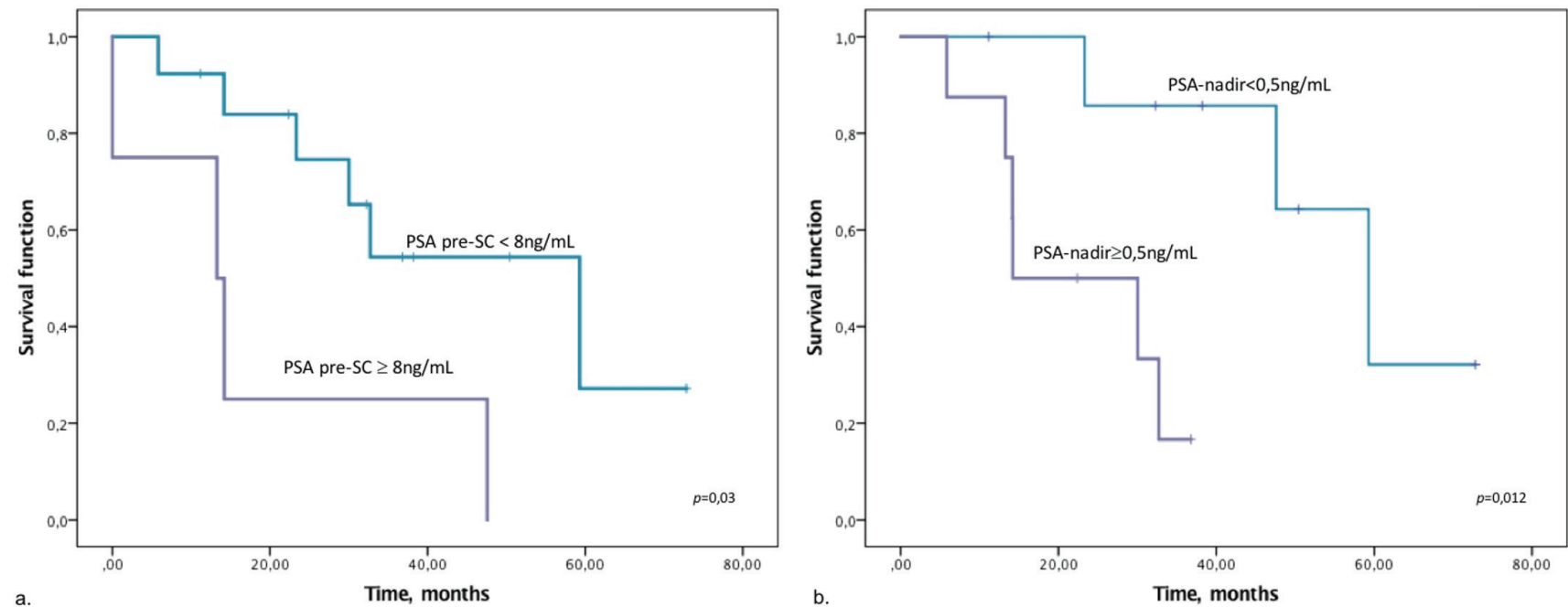

Figure 2. Kaplan-Meier curves of the biochemical progression-free survival of patients with recurrent prostate cancer treated with salvage cryotherapy (SC) stratified according to pre-SC prostate-specific antigen (PSA) ( $<8 \mathrm{vs} \geq 8 \mathrm{ng} / \mathrm{mL}$, log-rank test $\mathrm{p}=0.030$ ) (a.) and post-SC PSA nadir ( $<0.5 \mathrm{vs} \geq 0.5 \mathrm{ng} / \mathrm{mL}$, log-rank test $p=0.012)(b$.

40.28, $\mathrm{p}=0.126)$, and PSA nadir $\geq 0.5 \mathrm{ng} / \mathrm{mL}(\mathrm{HR} 0.51,95 \% \mathrm{Cl}$ $0.004-0.62, p=0.02$ ) as covariates.

The 3- and 5-year PCa-specific survival rates were 93.3\% and $85.6 \%$, respectively. The PCa-specific mortality of the studied population was $11 \%(n=2)$ with a mean survival time of 70.8 $(\mathrm{SE}=4.5)$ months.

\section{Discussion}

Over the past years, local salvage therapies for recurrent PCa have gained increasing attention as they might provide cancer control with minimal well-known side effects of ADT. Nevertheless, consensus about the best candidates for salvage treatment or the best approach is still not established. The current National Comprehensive Cancer Network guidelines suggest the following selection criteria: original clinical stage $\mathrm{T} 1-\mathrm{T} 2, \mathrm{Nx}$, or No, with pre-SC PSA level $\leq 10 \mathrm{ng} / \mathrm{mL}$, no distant metastasis, and a positive confirmatory biopsy (6). The European Urology Association guidelines recommend SRP to patients with biopsyproven recurrent $\mathrm{PCa}$ and consider alternative therapies such as HIFU or SC in the clinical trial setting. Although SRP remains the standard of care, no strong evidence supported its widespread use in this context (7). SRP carries significant morbidity with UI rate of 21\%-90\% and erectile dysfunction nearly in all patients (8). Furthermore, surgical complications are more common in SRP than in primary RP, such as urinary retention $(25.3 \%$ vs $3.5 \%)$, urinary fistula ( $4.2 \%$ vs $0.06 \%)$, and rectal injury ( $9.2 \%$ vs $0.6 \%$ (9). Cryoablation, also known as cryotherapy, has emerged as a valid option to achieve cancer control and experience fewer side effects. It involves the placement of probes within the prostate, which will reach extremely low temperatures using argon. The procedure comprises at least two freeze-thaw cycles. Rapid tissue freezing results in ice crystal formation and cell death (10). The free-hand technique, compared with the gridtemplate guided technique, allows the surgeon to make easier adjustments of the cryoprobes and anatomical landmarks. The main drawback of this technique is the requirement of a higher level of operator's expertise in prostate ultrasound imaging (11).

In an attempt to decrease the possible side effects of STC, namely, urinary retention (3.0\%-8.5\%), incontinence (4.4\%-13.0\%), rectourethral fistula (0\%-3.3\%), and erectile dysfunction (61.5\%-100\%) (11-13), investigators tried to apply SFC in patients with biopsy-proven unilateral recurrence. The technique was firstly described in 2008 by Eisenber (14).

In a study by Li et al. (15), SFC appears to be an effective treatment with encouraging potency preservation. However, SFC did not proved to be superior to STC regarding incontinence and rectourethral fistula. In this study, we found a higher rate of urinary acute retention and long-term UI in STC ( $p>0.05)$.

Tan et al. (16) found no significant difference in bPFS between the SFC and STC groups, after a median follow-up of 24 months, reporting a low rate of acute urinary retention in the SFC group.

One of the major concerns about focal therapy in PCa is its multifocality. Interestingly, recurrences after RT are more likely to be found at the same site of the primary tumor as a single index cancer (17), which when efficiently ablated reduces the postoperative PSA level by $\geq 80 \%$ (11). Although the index lesion is usually defined as the biopsy core with higher GS, radiation induces histological changes that limit Gleason interpretation in this setting (18) and can lead to a considerable false-positive (up to $60 \%$ ) and false-negative (up to $20 \%$ ) rates (19). Despite 
these limitations, in our institution, all positive biopsy cores were considered to define the candidates to SFC.

Another disadvantage of SFC is that, by leaving a prostate lobe untreated, postoperative PSA might remain high even with successful cancer control, which can be difficult for patient follow-up.

The 5- and 10-year bPFS rates of prostate SC vary between $47 \%$ and $63 \%$ and $35 \%$ and $30 \%$, respectively, based on data published retrospectively $(20,21)$. Early identification of candidates to salvage therapies is important as the tendency to delay treatment after recurrence appears to be associated with higher failure rates (22). We report a 5-year bPFS rate of 17.8\%, which can indicate that a significant proportion of patients had high pre-SC PSA levels. In our analysis, pre-SC PSA level $\geq 8$ $\mathrm{ng} / \mathrm{mL}$ was associated with a higher risk of tumor relapse with shorter bPFS (18.8 vs 46.1 months). Furthermore, patients with post-SC PSA nadir of $\geq 0.5 \mathrm{ng} / \mathrm{mL}$ showed inferior long-term outcome results, being an independent risk factor for bPFS.

A review published in 2012 reported that pre-SC PSA level $\geq 10$ $\mathrm{ng} / \mathrm{mL}$ is a predictor of PSA failure post-SC, which is in line with our results. Beyond that, PSA kinetics can be useful in predicting local or systemic recurrences, as a longer PSA-doubling time (>6-10 months) is associated with a higher likelihood of local recurrence (23).

After a median follow-up of 43.2 months, only 2 (11.8\%) patients received ADT. The possibility of sparing patients from the side effects of a non-curative treatment with ADT such as depression, loss of libido, diabetes, metabolic syndrome, and osteoporosis, is noteworthy (24).

\section{Study Limitations}

The main limitations of this study include its retrospective design, small sample size, and heterogeneous cohort.

\section{Conclusion}

SC appears to be a valid choice of salvage treatment for recurrent $\mathrm{PCa}$ with acceptable functional morbidity. Although $\mathrm{SC}$ showed inferior oncological results (cancer-specific survival and progression-free survival) to SRP, this disadvantage must be weighed against better functional outcomes. The superiority of SRP in a more durable biochemical control might be explained by the effect of lymph node dissection on controlling micrometastic disease and recurrence pattern of $\mathrm{PCa}$, i.e., in periurethral zone, which might be undertreated with SC. The selection of patients is important to tailor salvage treatments in recurrent $\mathrm{PCa}$, and series such as ours may help widen our views of an underused therapeutic method in recurrent PCa setting.

\section{Ethics}

Ethics Committee Approval: The institutional ethics committee conceded the approval for data collection, analysis, and publication of this retrospective study.

Informed Consent: Retrospective study.

Peer-review: Externally and internally peer-reviewed.

\section{Authorship Contributions}

Concept: L.A., R.C., R.F., A.M., Design: L.A., R.C., R.F., Data Collection or Processing: L.A., R.C., J.P., Analysis or Interpretation: L.A., R.C., J.P., R.F., I.B., A.M., Literature Search: L.A., R.C., Writing: L.A., R.C.

Conflict of Interest: No conflict of interest was declared by the authors.

Financial Disclosure: The authors declare that they have no relevant financial.

\section{References}

1. Ferlay J, Soerjomataram I, Dikshit R, Eser S, Mathers C, Rebelo M, Parkin DM, Forman D, Bray F. Cancer incidence and mortality worldwide: sources, methods and major patterns in GLOBOCAN 2012. Int J Cancer 2015;136:E359-386.

2. Artibani W, Porcaro AB, De Marco V, Cerruto MA, Siracusano S. Management of Biochemical Recurrence after Primary Curative Treatment for Prostate Cancer: A Review. Urol Int 2018;100:251-262.

3. Tran H, Kwok J, Pickles T, Tyldesley S, Black PC. Underutilization of local salvage therapy after radiation therapy for prostate cancer. Urol Oncol 2014:32:701-706.

4. Boissier R, Sanguedolce F, Territo A, Gaya J, Huguet J, Rodriguez-Faba 0 , Regis F, Gallioli A, Vedovo F, Martinez C, Palou J, Breda A. Partial salvage cryoablation of the prostate for local recurrent prostate cancer after primary radiotherapy: Step-by-step technique and outcomes. Urol Video J 2020;7:100040.

5. Kuru TH, Wadhwa K, Chang RTM, Echeverria LMC, Roethke M, Polson A, Rottenberg G, Koo B, Lawrence EM, Seidenader J, Gnanapragasam V, Axell R, Roth W, Warren A, Doble A, Muir G, Popert R, Schlemmer HP, Hadaschik $B A$, Kastner $C$. Definitions of terms, processes and a minimum dataset for transperineal prostate biopsies: a standardization approach of the Ginsburg Study Group for Enhanced Prostate Diagnostics. BJU Int 2013;112:568-577.

6. Aslam N, Nadeem K, Noreen R JAC. Prostate Cancer Prostate Cancer Abeloff's Clin Oncol 5/e 2015;8:938-944.

7. Mottet N, Bastian P, Bellmunt J, van den Bergh R, Bolla M, van Casteren NJ, Cornford P, Joniau S, Mason MD, Matveev V, van der Kwast TH, van der Poel $\mathrm{H}$, Rouviere 0 , Wiegel T. Guidelines on Prostate Cancer - Booklet. Eur Urol 2014;65:124-137.

8. Gotto GT, Yunis LH, Vora K, Eastham JA, Scardino PT, Rabbani F. Impact of prior prostate radiation on complications after radical prostatectomy. J Urol 2010;184:136-142.

9. Chade DC, Eastham J, Graefen M, Hu JC, Karnes RJ, Klotz L, Montorsi F, van Poppel H, Scardino PT, Shariat SF. Cancer control and functional outcomes of salvage radical prostatectomy for radiation-recurrent prostate cancer: a systematic review of the literature. Eur Urol 2012;61:961-971.

10. Mazur P. Cryobiology: The Freezing of Biological Systems. Science (80) 1970;168:939. LP - 949. Available from: http://science.sciencemag.org/ content/168/3934/939.abstract 
11. de Castro Abreu AL, Bahn D, Leslie S, Shoji S, Silverman P, Desai MM, Gill IS, Ukimura 0 . Salvage focal and salvage total cryoablation for locally recurrent prostate cancer after primary radiation therapy. BJU Int 2013;112:298-307.

12. Pisters LL, Rewcastle JC, Donnelly BJ, Lugnani FM, Katz AE, Jones JS. Salvage prostate cryoablation: initial results from the cryo on-line data registry. J Urol 2008;180:559-564.

13. Babaian RJ, Donnelly B, Bahn D, Baust JG, Dineen M, Ellis D, Katz A, Pisters $L$, Rukstalis D, Shinohara K, Thrasher JB. Best practice statement on cryosurgery for the treatment of localized prostate cancer. J Urol 2008;180:1993-2004.

14. Eisenberg ML, Shinohara K. Partial Salvage Cryoablation of the Prostate for Recurrent Prostate Cancer After Radiotherapy Failure. Urology 2008;72:1315-1318.

15. Li YH, Elshafei A, Agarwal G, Ruckle H, Powsang J, Jones JS. Salvage focal prostate cryoablation for locally recurrent prostate cancer after radiotherapy: initial results from the cryo on-line data registry. Prostate 2015;75:1-7.

16. Tan WP, ElShafei A, Aminsharifi A, Khalifa AO, Polascik TJ. Salvage Focal Cryotherapy Offers Similar Short-term Oncologic Control and Improved Urinary Function Compared with Salvage Whole Gland Cryotherapy for Radiation-resistant or Recurrent Prostate Cancer. Clin Genitourin Cancer 2020;18:e260-e265.

17. Huang WC, Kuroiwa K, Serio AM, Bianco FJ Jr, Fine SW, Shayegan B, Scardino PT, Eastham JA. The anatomical and pathological characteristics of irradiated prostate cancers may influence the oncological efficacy of salvage ablative therapies. J Urol 2007;177:1324-1329.
18. Egevad L, Delahunt B, Srigley JR, Samaratunga H. International Society of Urological Pathology (ISUP) grading of prostate cancer - An ISUP consensus on contemporary grading. APMIS 2016;124:433-435.

19. Crook J, Malone S, Perry G, Bahadur Y, Robertson S, Abdolell M. Postradiotherapy prostate biopsies: what do they really mean? results for 498 patients. Int J Radiat Oncol Biology Physics 2000;48:355-367.

20. Wenske $S$, Quarrier $S$, Katz AE. Salvage cryosurgery of the prostate for failure after primary radiotherapy or cryosurgery: long-term clinical, functional, and oncologic outcomes in a large cohort at a tertiary referral centre. Eur Urol 2013;64:1-7.

21. Williams AK, Martínez $\mathrm{CH}, \mathrm{Lu} \mathrm{C}, \mathrm{Ng}$ CK, Pautler SE, Chin JL. Disease-free survival following salvage cryotherapy for biopsy-proven radio-recurrent prostate cancer. Eur Urol 2011;60:405-410.

22. Stephenson AJ, Shariat SF, Zelefsky MJ, Kattan MW, Butler EB, Teh BS, Klein EA, Kupelian PA, Roehrborn CG, Pistenmaa DA, Pacholke HD, Liauw SL, Katz MS, Leibel SA, Scardino PT, Slawin KM. Salvage radiotherapy for recurrent prostate cancer after radical prostatectomy. JAMA 2004;291:1325-1332.

23. Kim-Sing C, Pickles T; Prostate Cohort Outcomes Initiative. Intervention after PSA failure: examination of intervention time and subsequent outcomes from a prospective patient database. Int J Radiat Oncol Biol Phys 2004;60:463-469.

24. Braga-Basaria M, Dobs AS, Muller DC, Carducci MA, John M, Egan J, Basaria S. Metabolic syndrome in men with prostate cancer undergoing long-term androgen-deprivation therapy. J Clin Oncol 2006;24:3979-3983. 